Por lo que respecta a la calidad del cuadro, es Carrillo un pintor tosco que no llega a alcanzar los niveles de los grandes bodegonistas del xvII. La manera en la que están conseguidas las calidades de los distintos objetos, dista mucho de la de los más destacados artistas de este género. A pesar de ello y, a diferencia de los mencionados con anterioridad, Carrillo introduce un elemento anecdótico en el cuadro que obliga al espectador a entrar en él. Esta inclusión, detalle muy barroco por otra parte, es debida a las figuras femeninas. Las dos miran directamente al espectador: la mujer señalando a la niña de rasgos velazqueños, quien come con delectación; por su parte, el perro trepa a la mesa en busca de las sobras. La figura mejor conseguida es la del hombre quien, en el centro de la composición, bebe de la jarra. Lo más interesante es el grupo formado por ambas mujeres de las cuales encontramos una réplica casi idéntica en «Cristo en casa de Marta y María” de Velázquez, en la National Gallery de Londres. Las más ancianas, en ambas composiciones, miran al espectador apuntando con sus índices a las niñas, quienes, a su vez, ya sea comiendo ya cocinando, dirigen la mirada hacia fuera del cuadro ${ }^{8}$. Sin querer comparar calidades, las miradas del de Carrillo son más vivas que en el bodegón de Velázquez. La conclusión que se obtiene de todo ello es que este tipo de distribución pudo ser frecuente y con algún significado que, todavía hoy, se nos escapa ${ }^{9}$.

En cuanto a los alimentos se refiere, se trata de una muestra de caza menor y, en general, de alimentos de invierno, como señalábamos anteriormente, incluida la gran coliflor del extremo inferior izquierdo.

Pero lo más importante en este cuadro, sin duda alguna, es la firma situada en el extremo superior izquierdo del papel que guarda unos granos -ipimienta?-. Esta firma se une a las ya mencionadas de pintores que cultivaron este género e indica el afán de autoría que demuestran estos artistas y que se les debería haber contagiado a otros más importantes, de los cuales no se conserva ningún cuadro autografiado. Aquí, por el contrario, el nombre escrito claramente en el centro de la composición, nos permite unir una obra a un pintor que carecía de ella y, otro factor importante, nos abre más puertas a la hora de una atribución de escenas de género que se hayan sin adscripción segura y de las cuales la pintura española del siglo xvi es tan abundante.

M. ${ }^{a}$ del Mar Doval Trueba Licenciada en Historia del Arte

\title{
«LA CARTA DE DOTE DE DOÑA JUANA PAULA COELLO, HIJA DEL PINTOR CLAUDIO COELLO» (1712)
}

Claudio Coello (1642-1693), contrajo un primer matrimonio, el 14 de marzo de 1674, con Doña Feliciana de Aguirre y Espinosa, de cuya unión nació un hijo bautizado en la parroquia de Santiago, el 26 de mayo de 1675, con el nombre de Bernardino. este enlace duró poco tiempo, ya que el día 22 de septiembre de 1675 fallecía, prematuramente, Doña Feliciana de Aguirre.

Dos años más tarde, concretamente el 15 de agosto de 1675, Claudio Coello volvía a casarse

\footnotetext{
8 Esta misma composición se encuentra en otro bodegón adquirido por el Museo del Prado recientemente; se trata de "Cristo en casa de Marta y María" de Joachim Beuckelaer. Ver "Catálogo de las Ultimas adquisiciones del Museo del Prado", 1995, n. 29.

9 Para los significados de los objetos dentro de los bodegones velazqueños, ver: CÉSAR PemÁn: "Acerca de los llamados almuerzos velazqueños", Archivo Español de Arte, 1961.
} 
con Doña Bernarda de la Torre, unión ésta que resultó muy prolífica, puesto que de ella nacieron seis hijos: Juana Gregoria, Juana Paula, Cristóbal Juan, Marcelo Tomás, Felipa Nicolasa y Manuela Estefanía ${ }^{1}$.

Doña Juana Paula Coello nació en Madrid en 1682, siendo bautizada en la parroquia de San Andrés el 20 de febrero de aquel año, actuando como padrino el pintor Juan Carreño de Miranda, buen amigo de su padre. Desconocemos cualquier dato sobre la vida de esta hija de Claudio Coello hasta que cumplió los treinta años, ya que a esa edad contrajo matrimonio con el viudo gaditano Don Alejandro López Ramírez, hijo de Don Francisco López Uriño y de Doña Paula Ramírez de Monsalves, ambos naturales de la citada ciudad andaluza.

El 21 de mayo de 1712, Don Alejandro López declaraba ante el escribano madrileño Domingo de Minuilla y Cuazo que «mediante la voluntad de Dios nuestro señor y para su santo servicio este tratado y dispuesto el que yo había de contraer matrimonio de segundas vodas con Doña Juana Paula Coello, de estado donzella, residente en esta Corte, hija lexitima de Don Claudio Coello, ya difunto, y de Doña Bernarda de la Torre, su muger, vezina de ella, de donde es natura] para lo cual están corridas las tres amonestaciones que dispone el santo concilio de Trento" ${ }^{2}$.

Con motivo de esta boda, Doña Bernarda de la Torre se comprometió a entregar a su futuro yerno «diferentes bienes y hacienda por dote y caudal de la dicha Doña Juana Paula Coello, su hija». A cambio de ello la viuda de Claudio Coello pedía a Don Alejandro López «la otorgue carta de pago y recivo de dote», a lo que este accedió «biendo se justo», declarando que «aora de presente recibo de mano de la dicha Doña Bernarda de la Torre, los vienes y hazienda propios de la referida Doña Juana Paula Coello».

La hija de Claudio Coello aportó a su matrimonio toda una serie de pertenencias que iban desde dinero a vestidos, pasando por muebles, esculturas, pinturas y algunas joyas de oro.

En dinero efectivo Doña Juana Paula Coello entrego a su futuro esposo la cantidad de 3000 reales de vellón, de los cuales 1620 fueron de contado, y el resto a cobrar de una manda, testamentaria que la dejó Doña María Murguía "para aiuda a tomar estado".

También llevó Doña Juana Paula Coello diversos vestidos y ropas de casa, tales como basquiñas, guardapiés, camisas, enaguas, cortinas, colchones, toallas, servilletas, almohadas mantillas, sábanas, colchas y mantas.

Como obras de arte que Doña Bernarda de la Torre entregó a su hija hay que mencionar cinco pinturas, entre ellas una Oración del huerto, tasada en 1000 reales de vellón, y una escultura de la Inmaculada Concepción, que el anónimo tasador de los bienes de la hija de Claudio Coello adju

\footnotetext{
1 Para todo lo relacionado con la familia de Claudio Coello véase Ciriaco Pérez Bustamante Claudio Coello. Noticias biográficas desconocidas en B.S.E.E., 1918, 26, 223-227 y más recientemente Edward J. Sullivan. Claudio Coello y la pintura barroca madrileña, Madrid, 1989.

2 Archivo Histórico de Protocolos. Protocolo = 14220, folios 151-153. "carta de dote que otorgo Don Alexandro López Ramírez en favor de Doña Juana Paula Coello en 21 de mayo de 1712.

- mas una ymagen de escultura de Nuestra Señora de la Conzepzion de Pedro Alonso, con su peana o trono dorado con quatro serafines, de bara y quarta de alto con su urna en que esta, de pal santo y marfil con su corredorzillo de bronzes, de dos varas de alto con poca diferencia y vidrios christales por delante y a los lados, y un bufete de lo propio de zinco quartas de largo, 3300 rs. - una pintura en lienzo de la oración del huerto, de dos varas y media de alto y tres de anchos con marco negro, 1000 rs. - otra pintura de la Samaritana, de dos terzias de alto y poco mas de una de ancho, con su marco negro, 120 rs. - dos floreros yguales, de dos terzias de alto y media bara de ancho, con sus marcos dorados, 100 rs. - otra pintura de nuestra señora de la Conzepzion, de dos bares de alto y bara y terzia de ancho, con su marco negro, 200 rs. - mas dos espexos iguales, sus lunas de a terzia de alto adiamantadas con marcos de peral, 60 rs. - dos escriptorios contadores de hevano y marfil en tres gavetas cada uno y de media bara de largo, 120 rs. - un escaparate de pino pintado de flores, de bara y media en quadro con poca diferenzia, con dos puertas que la zierran y en ellas bidrios ordinarios, y su pie asimismo de pino con tras cajones de zinco quartas de largo, 50 rs. - un bufetico bajo de granadillo, de tres quartas de largo y media bara de ancho con dos cajonzitos por delante, $60 \mathrm{rs}$.
} 
dica a Pedro Alonso de los Ríos ${ }^{3}$. La imagen, que se levantaba sobre una peana formada por cuatro serafines, estaba guardada en una suntuosa urna de palo santo y marfil y adornada con un corredor de bronce. Todo ello fue valorado en la elevada cantidad de 3300 reales de vellón.

Entre los muebles se contaban varios espejos, dos contadores de ébano y márfil y un bufete de granadillo. Muy pocas fueron las joyas que Doña Juana Paula Coello llevó a su matrimonio, limitándose a dos arillos de oro y una sortija del mismo metal, adornada con «un ojo de bivora».

Digamos como algo a destacar es que entre los testigos de la citada carta de pago aparece el pintor Juan Delgado.

José Luis BARrio Moya Institución de Estudios Complutenses

${ }^{3}$ Se trata del escultor vallisoletano Pedro Alonso de los Ríos, buen amigo de Claudio Coello, y padrino de su hija Juana Gregoria. 